\title{
Relações de gênero como categoria transversal na historiografia contemporânea ${ }^{1}$
}

\author{
Joana Maria Pedro
}

Historiadoras/es que não se dedicam aos estudos de gênero têm incorporado essa categoria em sua escrita da história e nas suas reflexôes. Alguns exemplos na historiografia brasileira podem ser citados: Sidney Chalhoub, em Machado de Assis: historiador; ${ }^{2}$ Angela de Castro Gomes, no prólogo do livro Escrita de si, escrita da história. ${ }^{3} \mathrm{O}$ mais comum, entretanto, é apenas incluir a categoria "mulher". Outros, porém, apesar de trazerem contribuições importantes para a historiografia, não se beneficiam das possibilidades que a categoria "gênero" pode oferecer para as reflexões do que pesquisam. E não se trata, em absoluto, de falta de fontes; quem trabalha com memória e relatos orais, por exemplo, sabe que as mulheres são as principais depoentes. Trata-se de um dado demográfico e, ao mesmo tempo, uma questão de gênero. ${ }^{4}$ Sabemos, também, que os acervos que permitem a pesquisa das grandes figuras do mundo público foram guardados, principalmente, pelas esposas, filhas, netas. Elas têm sido as guardiãs da memória. Mesmo assim, algumas pessoas parecem achar que as categorias "gênero" ou "mulheres", "mulher", "masculinidades", "feminilidades", em nada contribuem para o conhecimento que constroem.

Volto, entretanto, a reafirmar que, nos dias atuais, é crescente o número de pessoas que incorporam em suas análises as diferenças de gênero para observar os impactos dos acontecimentos sobre homens e mulheres, a forma como a fonte é constituída, os dados que podem ser coletados e a maneira como se vai criticar a fonte. Historiadores de fama internacional, como Eric Hobsbawm ${ }^{5}$ e Roger Chartier, ${ }^{6}$ além de outros, vêm afirmando que a Revolução das Mulheres foi um dos grandes acontecimentos do século XX, e que a dominação de gênero permeia as relações.

Françoise Thébaud informa que, só recentemente, a historiografia francesa passou a usar com mais frequência a categoria "gênero". Palavra, aliás, considerada imprópria pela Comissão Geral de Terminologia e de Neologia, que atua junto ao primeiro-ministro. A palavra genre, como tradução para gender, foi considerada "neologismo e anglicanismo". Ela pergunta se isso é apenas defesa da língua francesa."

De acordo com essa autora, a historiografia francesa foi, por muito tempo, um ofício de homens. Estes escreveram uma história para homens, apresentada como universal. Era uma "história assexuada, que esquecia a diferença dos sexos e o masculino no homem". ${ }^{8}$ A Escola dos Annales, por exemplo, era uma "confraria masculina", utilizando muitas vezes o trabalho gratuito de mulheres, em geral suas esposas, as quais eram encontradas como estudantes, nos bancos das faculdades. ${ }^{9}$ Poucos historiadores fazem referência a esse trabalho gratuito, nos prólogos de seus livros. ${ }^{10}$

Já sabemos quanto o feminismo, o movimento de mulheres e o de gays e lésbicas ${ }^{11}$ têm contribuído para que as reflexôes sobre gênero sejam implementadas de forma interdisciplinar. $\mathrm{O}$ campo historiográfico, entretanto, tem sido um dos mais resistentes. A acusação de ser uma "história militante", portanto, não "científica”, continua a assombrar, mesmo quando há muito já se abandonou a certeza da neutralidade. É ainda interessante refletir como, da mesma forma, outras categorias como "classe", "raça/etnia", "geração" também são tributárias de movimentos sociais e, obviamente, ligadas a contextos específicos; no entanto, não parecem sofrer a mesma "desconfiança" e desqualificação.

Considero, com Reinhart Koselleck, ${ }^{12}$ que as categorias de análise têm história e, inspirada em Roger Chartier, ${ }^{13}$ que elas são apropriadas por historiadoras e historiadores e instrumentalizadas pelos movimentos sociais. E é dessa forma que pretendo mostrar como as categorias "mulher", "mulheres" e "relações de gênero" têm sido formuladas, divulgadas e apropriadas em diferentes locais. Focalizarei principalmente alguns países do Cone Sul, como o Brasil, a Argentina, o Paraguai e a Bolívia, por meio dos títulos das obras de história ou pelo fato de incorporarem em seu texto essas categorias. 
Clare Hemmings, em "Contando estórias feministas", lembra que a história do feminismo - denominado, por ela, de "estória", para relativizar - tem sido uma narrativa hegemonicamente definida pelo hemisfério norte. ${ }^{14}$ É essa discussão que me leva a interrogar de que maneira essa "estória" é narrada pela historiografia feminista do Cone Sul. De que maneira as categorias como "mulher", "mulheres" e "relações de gênero" são apropriadas?

Nas narrativas do feminismo existe a noção de que essas ideias têm formado várias ondas. Na Primeira Onda (final do século XIX e início do XX), as mulheres reivindicavam direitos políticos, sociais e econômicos; na Segunda Onda (a partir da metade dos anos 1960), elas passaram a exigir direito ao corpo, ao prazer, e lutavam contra o patriarcado.

De acordo com a autora, tem sido recorrente uma narrativa do feminismo de Segunda Onda, na qual

...um feminismo essencialista universalizado é direta ou indiretamente associado aos anos 70 , e críticas raciais e sexuais são contidas nos anos 80 para que o pós-estruturalismo possa, finalmente, superar o essencialismo e incorporar as identidades associadas à diferença sexual, sexualidade e raça. ${ }^{15}$

Essa narrativa, caracterizada por deslocamentos lineares, atribui a cada uma dessas décadas a emergência de uma categoria de análise. Assim, nos anos 1970, a categoria seria a de "mulher", pensada como a que identificaria a unidade, a irmandade, e ligada ao feminismo radical. Os anos 1980 seriam aqueles identificados com a emergência da categoria "mulheres", resultado da crítica das feministas negras e do Terceiro Mundo. O feminismo dos 1990 seria o da categoria "relaçôes de gênero", resultado da virada linguística e, portanto, ligada ao pós-estruturalismo e, por fim, à própria crítica a essa categoria, encabeçada por Judith Butler. ${ }^{16}$ A historiografia do Cone Sul teria acompanhado essas ondas? Em quais décadas isso teria ocorrido?

Convém sublinhar que pensar o feminismo a partir de diferentes ondas reforça a ideia da existência de centros irradiadores e suas margens; é como se uma pedra tivesse sido atirada na água, formando várias ondas. Elas vão se abrindo e apontando para a circulação de discursos e teorias que partem de um centro produtor - em geral, países considerados desenvolvidos do hemisfério norte - e se dirigem para o hemisfério sul, localização principal dos países considerados subdesenvolvidos. Contudo, o que temos encontrado na historiografia de vários países do Cone Sul é, em primeiro lugar, a confirmação da existência de "ondas", em que certas categorias emergem - muitas vezes com "atraso" em relação aos "centros emissores" - no campo historiográfico; em segundo lugar, que as novas categorias que surgem não fazem, no entanto, desaparecer as anteriores. Convivem lado a lado, em pleno século XXI. Outra questão importante: muito da história que se escreve não é realizado apenas por historiadoras, mas também e principalmente por sociólogas e antropólogas.

O trabalho intitulado $A$ mulher no Brasil, ${ }^{17}$ da historiadora brasilianista June Hahner, foi publicado no Brasil já em 1978, portanto ainda na década de 1970, momento considerado de emergência da categoria "mulher". O mesmo ocorreu com a tradução da obra de C. R. Boxer, A mulher na expansão ultramarina ibérica (1415-1815): alguns factos, ideias e personalidades, lançado no Brasil em 1977. Foi ainda nos anos 1970 que se publicou $A$ mulher na sociedade de classes: mito e realidade, ${ }^{18}$ da socióloga Heleieth Iara Bongiovani Saffioti. Destaque-se, ainda, que este trabalho, apesar de não ser historiográfico, esteve presente no relato de vários indivíduos que se identificaram com o feminismo no período. Foi lido em grupos de estudo e consciência por aqueles, envolvidos com a resistência à ditadura, que estavam no exílio. ${ }^{19}$

Embora os anos 1980 sejam considerados pelo feminismo internacional o período da emergência da categoria "mulheres" já referida acima, no Brasil e em outros países do Cone Sul, a "mulher" continuava presente nos títulos das produções historiográficas, como A mulher na história do Brasil, de Mary Del Priore, publicado em 1988; ${ }^{20}$ A mulher do Rio de Janeiro no século XIX: um indice de referências em livros de viajantes estrangeiros, de Miriam Lifchitz Moreira Leite, publicado em 1982; ${ }^{21}$ Submissão e resistência: a mulher na luta contra a escravidão, de Maria Lucia de Barros Mott, publicado em 1988. ${ }^{22}$ Outras obras, tanto nos anos $1980^{23}$ como nos $1990,{ }^{24}$ continuaram empregando essa categoria. Do historia- 
dor Luciano Figueiredo, por exemplo, foi lançado, em 1993, $O$ avesso da memória: cotidiano e trabalho da mulher em Minas Gerais no século XVIII. ${ }^{25}$ Da mesma forma, até hoje essa categoria continua presente nos títulos de obras voltadas para a história do Brasil. ${ }^{26}$

Em alguns países do Cone Sul, também é possível encontrar obras em cujo título aparece a categoria mujer. Em 1978, no Chile, Lucia Santa Cruz e outras autoras escreveram Tres ensayos sobre la mujer chilena: siglos XVIII-XIX-XX,27 em 1988, na Bolívia, Beatriz Rossells publicava La mujer: una ilusion. Ideologías e imágenes de la mujer en Bolivia en el siglo XIX. ${ }^{28}$

Nessa narrativa acerca das "ondas", os anos 1980, como dito anteriormente, teriam testemunhado a emergência da categoria "mulheres". Foi, entretanto, nos anos 1990 que a categoria ganhou mais destaque, por intermédio dos cinco volumes da coleção História das mulheres no Ocidente, impressos na França entre 1991 e 1992 e traduzidos para dez línguas diferentes, constituindo um grande sucesso editorial. No Brasil, esses livros chegaram a partir de $1993,{ }^{29}$ publicados em português pela Editora Afrontamento, da cidade do Porto, em Portugal, e distribuídos no Brasil pela Ebradil, de São Paulo. ${ }^{30}$ Esse mesmo sucesso promoveu a edição de similares em diversos países. Aqui, o livro História das mulheres no Brasil veio a público em 1997, coordenado por Mary Del Priore. ${ }^{31}$ O mesmo ocorreu com Historia de las mujeres en la Argentina, formado por dois volumes, lançados em $2000 .{ }^{32} \mathrm{Na}$ Espanha, foi publicada uma coleção de quatro volumes sob o título Historia de las mujeres en España y América Latina, cujo último volume saiu em 2006. ${ }^{33}$ Portanto, tratava-se de um sucesso de público, muitas vezes, imitado.

Inúmeras obras brasileiras já utilizavam a categoria "mulheres" desde os anos 1980. Em 1984, por exemplo, Maria Odila Leite da Silva Dias publicava Quotidiano e poder em São Paulo no século XIX ${ }^{34}$ que, embora não trouxesse no título a palavra "mulheres", foi, de fato, essa, a principal categoria utilizada. Isso também pode ser observado nas obras de Martha de Abreu Esteves, Meninas perdidas: os populares e o cotidiano do amor no Rio de Janeiro da Belle Époque, ${ }^{35}$ de Luzia Margareth Rago, Do cabaré ao lar: a utopia da cidade disciplinar, Brasil 1890-1930,36 e de Magali Engel, em Meretrizes e doutores: saber médico e prostituição no Rio de Janeiro (1840-1890). ${ }^{37}$ Também foi publicado, nos anos 1980, o trabalho de Rachel Soihet, Condição feminina e formas de violência: mulheres pobres e ordem urbana, 1890$1920,{ }^{38}$ e o de Eni de Mesquita Samara, As mulheres, o poder e a família: São Paulo século XIX. ${ }^{39}$ Ainda em 1989, lançou-se, na Revista Brasileira de História, um número inteiramente dedicado ao tema da "mulher", intitulado "A mulher no espaço público". Tratava-se do número 18, volume 9, organizado por Maria Stella Martins Bresciani. Em sua apresentação, a organizadora dizia que essa era uma "história da exclusão".$^{40}$ Falar de mulher na história significava, então, tentar reparar, em parte, essa exclusão, uma vez que procurar traços da presença feminina em um domínio sempre reservado aos homens era uma tarefa difícil. Nesse número, categorias como "mulher", "mulheres", "condição feminina” eram utilizadas nas análises das fontes e nas narrativas que eram tecidas. ${ }^{41}$

Em diferentes países do Cone Sul, a História das Mulheres, além das coletâneas já mencionadas, encontra-se em diversas temporalidades, nunca seguindo as marcas temporais das "ondas", nem mesmo com atraso. $\mathrm{Na}$ verdade, em um mesmo período encontram-se discussões historiográficas que partem da categoria "mulher" e da categoria "mulheres", indistintamente. Assim como no Brasil, várias profissionais, oriundas da Sociologia, da Antropologia, da área da Literatura, escrevem sobre a História das Mulheres, não se constituindo, portanto, numa tarefa unicamente de historiadoras. Datam de 2007 duas obras com essa categoria, na Argentina: Mujeres en la sociedad argentina: una historia de cinco siglos, de Dora Barrancos (socióloga e historiadora); e Historias de luchas, resistencias y representaciones. Mujeres en la Argentina, siglos XIX y XX, escrita por três historiadoras..$^{42}$ No Chile, Lavrin Asunción, também historiadora, publicou em 2005 Mujeres, feminismo y cambio social en Argentina, Chile y Uruguay 18901940; ${ }^{43}$ Teresa Valdés, socióloga, e Marisa Weinstein lançaram em 1993 Mujeres que sueñam. Las organizaciones de pobladoras en Chile: 1973-1989. ${ }^{44}$ Em 2005, Edda Gaviola, Eliana Largo, antropóloga, e Sandra Palestro publicaram Una historia necesaria. Mujeres en Chile: 1973-1990. Em 2008, Sonia Montecino Aguirre, antropóloga, publicou Mujeres chilenas. Fragmentos de una historia. ${ }^{45}$ 
No Paraguai, o panorama é semelhante. Nos anos 1990, e mesmo no início do século XXI, vários trabalhos focalizando a História das Mulheres foram publicados, por diferentes profissionais das ciências humanas. Em 1993, Line Bareiro, da Sociologia Política, Clyde Soto, que se autodenomina investigadora social, e Mary Monte lançaram Alquimistas: documentos para otra historia da las mujeres, considerado um marco para a História das Mulheres, no Paraguai. Em 2001, Nadimy Perla Yore e Carmen Colazo publicaram Al rescate de nuestra historia, no qual narram a formação dos primeiros grupos de mulheres que surgiram a partir dos anos $1980 .{ }^{46}$ Ainda em 2003, Olga Caballero Aquino, também da área das Ciências Sociais, publicou Por orden superior. Testimonios de mujeres victimas de la dictadura en Paraguay: $1954-1989 .{ }^{47}$

Somente no ano de 2010, em Historia del Paraguay, foi publicado o trabalho de uma historiadora, Barbara Potthast, que contribui com um capítulo intitulado "La mujer en la historia del Paraguay". ${ }^{4}$ De acordo com a autora, não há uma "verdadeira história da mulher" no Paraguai, há somente histórias de algumas mulheres que se tornaram famosas. Pouca coisa se escreveu nesse campo. ${ }^{49}$

Voltando às "ondas", teria acontecido nos anos 1990 a grande divulgação da categoria "gênero". O trabalho da historiadora Joan Scott representa um marco nessa discussão. No final da década de 1980, a categoria já vinha sendo empregada em diferentes disciplinas, entre as quais, psicanálise, antropologia, sociologia, literatura. Foi em 1986, porém, que Scott publicou nos Estados Unidos, na The American Historical Review, o artigo que viria a ser traduzido na França em 1988, publicado no Les Cahiers du GRIF50 e no Brasil, em 1990, na revista Educação e Realidade, sob o título de "Gênero, uma categoria útil de análise histórica", ${ }^{1}$ e que passaria a ser inúmeras vezes citado. O trecho mencionado com mais frequência é certamente este: "... gênero é um elemento constitutivo de relaçôes sociais fundadas sobre as diferenças percebidas entre os sexos e o gênero é um primeiro modo de dar significado às relações de poder" ${ }^{52}$

Nesse artigo, a autora salienta que a disciplina História não era apenas o registro, e sim a forma como os sexos se organizavam e dividiam tarefas e funções através do tempo. A história era, ela mesma, responsável pela "produção da diferença sexual", ${ }^{3}$ pois uma narrativa histórica nunca é neutra e, quando apenas relata fatos em que homens estiveram envolvidos, constrói, no presente, o gênero. A história, nesse caso, é uma narrativa sobre o sexo masculino e constitui o gênero ao definir que somente, ou principalmente, os homens fazem história. Além disso, falar de gênero significava deixar de focalizar a "mulher" ou as "mulheres"; tratava-se de relações entre homens e mulheres, mas também entre mulheres e entre homens. Nessas relaçôes, o gênero se constituiria.

Apesar de o artigo de Joan Scott ser muito citado, tanto no Brasil como em outros países do Cone Sul, e a palavra "gênero" constar no título das obras, o conteúdo continua falando de "mulheres", reforçando assim a ideia corrente no senso comum, de que "gênero" seria sinônimo de "estudo sobre mulheres". Mesmo assim, são publicados inúmeros trabalhos - não necessariamente escritos por historiadoras - que utilizam a categoria "gênero", tanto no título como nas análises que fazem.

No Brasil, é possível encontrar inúmeros desses trabalhos. Destacamos, dentre eles: em 1997, o livro organizado por Eni de Mesquita Samara, Rachel Soihet e Maria Izilda Santos de Matos, Gênero em debate: trajetória e perspectivas na historiografia contemporânea ${ }^{54}$ ainda em 1997, escrito por Mônica Raisa Schpun, Gênero sem fronteiras: oito olhares sobre mulheres e relaçôes de gênero, ${ }^{55} \mathrm{em} 2003$, Durval Muniz de Albuquerque Júnior publicou Nordestino: uma invenção do falo. Uma história do gênero masculino (Nordeste - 1920-1940); ${ }^{56}$ e, em 2004, Cristiani Bereta da Silva lançou Homens e Mulheres em movimento: relaçôes de gênero e subjetividades no MST. ${ }^{57}$

Nos demais países do Cone Sul, as discussões de gênero no interior da produção historiográfica são até mais antigas. Em 1993, Dora Barrancos, na Argentina, editou Historia y género; ${ }^{58}$ em 1997, Elizabeth Jelin, também argentina, publicou no Chile, Los derechos de la cultura de género. ${ }^{59}$ Nesse mesmo país, Claudia Darrigrandi Navarro lançou, também em 2001, Dramaturgia y género en el Chile de los sesenta; ${ }^{60}$ no mesmo ano e na mesma cidade, Rachel Olea e Olga Grau organizaram o livro Volver a la 
memoria. ${ }^{61}$ Andrea Andújar, Nora Domínguez e María Inés Rodríguez publicaram, em 2005, a coletânea Historia, género y política en los '70;62 em 2009, em Buenos Aires, foi lançado, de Paola Martinez, Género, política y revolución en los años setenta. Las mujeres del PRT-ERP. ${ }^{63}$

Evidentemente, esses não são todos os livros de história publicados, porém é preciso salientar que a historiografia do Cone Sul apropriou-se muito pouco da categoria "gênero", mais presente, entretanto, em trabalhos de Sociologia, às vezes, com caráter interdisciplinar.

Em países como Bolívia e Paraguai, o uso da categoria "gênero" não seguiu as mesmas etapas que se verificaram em outros países. Nesses lugares, as discussões sobre "mulher", "mulheres" e "gênero" vieram juntas, principalmente a partir de meados dos anos 1980. Muitas vezes, foram investimentos internacionais na formação de quadros para constituição de ONGs que trouxeram essas discussões. Segundo Carmen Echauri, ${ }^{64}$ foi a participação na Conferência de Nairóbi, em 1985, com o impulso das Nações Unidas, que marcou a retomada do feminismo no Paraguai. Nos depoimentos das mulheres que hoje se consideram feministas, há relatos, nesses dois países, de cursos ministrados sobre relações de gênero, realizados no final dos anos 1990 e início do século XXI. Lourdes Monteiro, da Bolívia, por exemplo, narrou que fez Especialização em Gênero na Universidade Estatal da Bolívia. Gloria Rubin e Teresita Silvero narraram recursos conseguidos para promover cursos sobre gênero no Paraguai.

Contudo, é bom lembrar, esses investimentos ainda não se refletiram suficientemente na historiografia. Em outros campos disciplinares, entretanto, podem ser encontradas obras que empregam a categoria "gênero" em suas análises.

No campo acadêmico, observa-se ainda tensões e conflitos que se expressam nas disputas entre categorias como "feminismo" e "gênero". Na Argentina, Alejandra Ciriza, filósofa e professora na Universidade Nacional de Cuyo, em Mendoza - cuja trajetória pessoal foi marcada pelo cárcere do regime militar, motivação para diversas pesquisas que realizou no campo da Filosofia-,${ }^{65}$ afirma:

Eu faço estudos feministas, eu não faço estudos de gênero. [...] Pessoalmente eu sou reticente ao uso da categoria gênero por razões de ordem disciplinar, já que no campo da Filosofia o uso desta categoria não é tão simples. É uma categoria, em primeiro lugar, nascida dentro de uma determinada tradição e ligada a uma determinada língua, então gente que vem de outras tradições - no meu caso eu sou muito mais ligada à tradição francesa e à tradição continental - tem muita dificuldade para incorporar um termo como gênero. Prefiro teoria feminista ou filosofia feminista, que é o que eu faço, porque fazem referência ao sujeito político do feminismo, já que eu creio e tento sustentar a necessidade de uma articulação forte entre teoria e política. ${ }^{66}$

Essa crítica é muito presente na Argentina, porém bem menos em outros países do Cone Sul. Reflete as tentativas de delimitação, dentro da academia, entre as intelectuais que estariam mais próximas da militância - e que utilizam a categoria "feminismo" - e aquelas consideradas mais distantes, que utilizam a categoria "gênero".

Observa-se esse questionamento da categoria "gênero" em diversos espaços acadêmicos, e não somente na tensão entre academia e militância. Para autoras como Teresa Aguilar García, depois da "Segunda Onda" do feminismo, estaríamos vivendo a terceira onda: a da pós-modernidade. Momento em que se debatem o feminismo cultural e o ecofeminismo com o feminismo de quarta onda, que incluiria o feminismo queer de Judith Butler e o cyberfeminismo de Donna Haraway. ${ }^{67}$ Assim, nos países do Cone Sul - para atender às exigências dos fundos de financiamento para o desenvolvimento e para conseguir recursos para os vários projetos sociais -, as mulheres identificadas com o feminismo recorriam instrumentalmente ao "gênero", fazendo cursos, escrevendo textos, produzindo histórias com essa categoria. Por outro lado, nos países ditos centrais, onde se encontram, principalmente, os recursos que financiam tais projetos, é possível notar uma desconfiança em relação à categoria "gênero", liderada pelas teóricas pós-estruturalistas e desconstrucionistas. A causa dessa desconfiança é a de que, por melhores intenções que se tenha, a categoria mantém a "diferença sexual" como importante. 
Judith Butler busca destruir o sistema binário que opõe natureza (sexo) e cultura (gênero), o eu e o outro, e defende que "o sexo não é dado biologicamente, sobre o qual o gênero é construído"; ao contrário, é apenas um ideal regulativo materializado num corpo por meio de práticas normativas reiteradas. ${ }^{68}$

O que se nega agora é que as diferenças marquem o comportamento sexual das pessoas por toda a vida. $\mathrm{Na}$ verdade, o que se pede é a desaparição da noção de identidade de gênero. Judith Butler, por exemplo, sustenta que a identidade de gênero é útil à dominação masculina. ${ }^{69}$ Quando, em 1990, ela propôs a "performatividade do gênero", afirmou que gênero é uma construção cultural e que, portanto, não é resultado do sexo nem tão aparentemente fixo como o sexo. ${ }^{70}$

A categoria de análise "gênero" passa, portanto, por intenso bombardeio, e não só por ser acusada de ser útil à dominação. É também considerada desmobilizante para o feminismo. O que se reivindica é a retomada da categoria "mulher", não mais na perspectiva anterior, universal e determinada pela biologia. Argumenta-se que, agora, o uso dessa categoria seria bem-vindo, pois se trataria de um "essencialismo estratégico", ${ }^{71}$ ou uma "categoria situada", ${ }^{72}$ visando à mobilização política. Nessa discussão, Claudia Lima Costa lembra-nos que o uso da categoria tem criado impasses teóricos, cuja saída seria definir "mulher como posicionalidade", ${ }^{73}$ ou seja, a solução seria observar quem utiliza e como está sendo utilizada a categoria.

Paralelamente, constata-se outra discussão no interior do feminismo, muito recente na historiografia no Cone Sul: a articulação entre gênero e pós-colonialismo. O pressuposto é de que, a partir das margens, e não a partir do "centro", é possível ler melhor o mundo e, assim, elaborar um projeto crítico e transformador, com uma nova visão de futuro. ${ }^{74}$ Essas pesquisadoras, nem todas historiadoras, têm sido influenciadas por intelectuais como Gayatri Chakravorty Spivak, ${ }^{75}$ autor de importantes reflexôes sobre as sociedades terceiro-mundistas. A crítica pós-colonial reconsidera a história a partir dos colonizados, e tenta recuperar as "vozes baixas" da história. Questiona os estatutos assumidos pela historiografia ocidental, suas omissóes, suas perspectivas. $\mathrm{O}$ conhecimento ocidental, de acordo com essa abordagem, está colonizado e deveria ser descolonizado para incluir outras formas de gerar conhecimento. ${ }^{76}$

Entre as intelectuais que adotam essa abordagem, uma das mais citadas é Gloria Anzaldúa, que propõe assumir a "consciência mestiça", colocando-se numa posição de fronteira geográfica e sexual em vista de sua própria identidade chicana, lesbiana e não branca. ${ }^{77}$

Ela mesma explica essa noção:

Comecei a pensar: Sim, sou chicana, mas isso não define quem eu sou. Sim, sou mulher, mas isso também não me define. Sim, sou lésbica, mas isso não define tudo que sou. Sim, venho da classe proletária, mas não sou mais da classe proletária. Sim, venho de uma mestiçagem, mas quais são as partes dessa mestiçagem que se tornam privilegiadas? Só a parte espanhola, não a indígena ou negra. Comecei a pensar em termos de consciência mestiça. O que acontece com gente como eu que está ali no entre-lugar de todas essas categorias diferentes? O que é que isso faz com nossos conceitos de nacionalismo, de raça, de etnia, e mesmo de gênero? Eu estava tentando articular e criar uma teoria de existência nas fronteiras. [...] Eu precisava, por conta própria, achar algum outro termo que pudesse descrever um nacionalismo mais poroso, aberto a outras categorias de identidade. ${ }^{78}$

O argumento de Gloria Anzaldúa caminha no sentido contrário ao da noção de "ondas”, já referida anteriormente, as quais partiriam de um centro irradiador. Ela questiona as feministas brancas por se considerarem as "inventoras" do questionamento da opressão sexista. Pergunta por que elas não podem deduzir que as próprias mulheres não brancas, que vivem cada dia em situação opressiva, não possam adquirir consciência dessa política patriarcal e desenvolver estratégias de resistência por conta própria. E ela ainda provoca: se as mulheres negras de classe média tivessem começado um movimento se autoclassificando como oprimidas, alguém as teria levado a sério? ${ }^{79}$

Em relação aos países do Cone Sul, por exemplo, essa abordagem tem afirmado que "nas formações sociais pré-hispânicas existia igualdade de gênero", que havia a valorização, de forma igualitária, 
das tarefas realizadas pelos dois sexos - promovendo a complementaridade do casal. Além disso, cada divindade masculina tinha seu correspondente feminino ${ }^{80}$ Nessa perspectiva, teria sido a colonização europeia que promoveu as desigualdades de gênero.

Não resta dúvida de que nessa abordagem há uma alta dose de leitura romântica do passado pré-colonial. Por outro lado, essa interpretação tem sido bastante fértil em discussões de gênero, articulando história, antropologia e sociologia. Destaque-se, ainda, que a abordagem focaliza principalmente as interseçõos entre gênero, raça/etnia e classe.

$\mathrm{Na}$ Bolívia, por exemplo, a questão indígena articula-se com o feminismo e o movimento de mulheres de maneira muito peculiar. Marisol Cadena, em artigo publicado na revista Estudios y Debates, lembra-nos que, nos Andes, "las mujeres son más indias", ou seja, na relação que cruza gênero e raça, os homens são menos desqualificados por suas origens nativas que as mulheres. ${ }^{81} \mathrm{Na}$ pesquisa, constatamos que, nesse mesmo país, a presença de um feminismo "indígena”, cujas mulheres retomaram trajes considerados indígenas como forma de identificação e, ao mesmo tempo, usam a categoria "gênero" nos seus discursos e relações com o Estado e com órgãos financiadores internacionais. Por outro lado, Cecilia Salazar ${ }^{82}$ afirma que esse "traje indígena" é, na verdade, uma invenção de tradiçōes. A pollera, ${ }^{83}$ considerada "original", surgiu no período colonial espanhol e era usada pelas senhoras espanholas.

No movimento indígena, há um discurso de que, em suas culturas, não há problemas de gênero; entretanto, nas assembleias comunais os dirigentes falam em espanhol - idioma que as mulheres não conhecem. Eles deixam o idioma nativo para questôes privadas e domésticas. É muito alto o analfabetismo feminino e os homens têm fortes privilégios de alimentação: "El hombre come más no porque trabaje mas sino porque es hombre." ${ }^{4}$

$\mathrm{Na}$ divisão internacional de produção teórica, costumeiramente, é no "Norte" que se constituem as teorias e no "Sul" que se fazem os estudos de caso. É o Norte quem dita qual teoria é mais importante e legítima, e qual é a menos "correta", a mais atrasada. A abordagem pós-estruturalista, por exemplo, excluiu do vocabulário teórico legítimo a categoria "mulher", acusando-a de ser essencialista. Entretanto, para as historiadoras do Cone Sul, as categorias "mulher" e "mulheres" continuam muito presentes.

Caminhando para a conclusão, gostaria de apontar que, também no Brasil, houve, nos anos 1970, 1980 e início dos 1990, uma concentração de estudos sobre "mulher", "mulheres" e, depois, "relações de gênero", em regiōes consideradas "centrais", como São Paulo e Rio de Janeiro. ${ }^{85}$ Porém, desde meados dos anos 1990, observa-se um deslocamento em direção a outras regiōes. Atualmente, são considerados locais por excelência dos estudos de gênero, nesta ordem: Florianópolis, onde a Universidade Federal de Santa Catarina publica a Revista Estudos Feministas e desenvolve o Projeto Fazendo Gênero, vinculado ao Instituto de Estudos de Gênero da UFSC; Salvador, com o Núcleo de Estudos Interdisciplinares sobre a Mulher (NEIM) e, atualmente, com o Programa de Pós-graduação em Estudos Interdisciplinares sobre Mulheres, Gênero e Feminismo, ambos na Universidade Federal da Bahia; e, ainda, Campinas, com o Núcleo de Estudos de Gênero Pagu e a revista Cadernos Pagu, ${ }^{86}$ ambos no âmbito das atividades acadêmicas da UNICAMP.

Penso que alguns dados do Seminário Internacional Fazendo Gênero 9, realizado em agosto de 2010 em Florianópolis, podem nos ajudar a situar esse campo de estudos no Brasil e, principalmente, na historiografia. Ressalto que esse evento acontece a cada dois anos, tendo começado em 1994. Sua característica é a interdisciplinaridade, reunindo especialistas e interessados que discutem não somente relações de gênero, mas, feminismo, mulher, mulheres etc. Em 2010, na nona versão, o evento contou com 4.033 inscritos, dos quais apenas 807 (20\% do total) eram homens, portanto, um evento significativamente feminino. Dos 1.875 trabalhos apresentados nos 96 Simpósios Temáticos, 260 eram de História, representando, portanto, apenas $13,86 \%$ do total. Isso mostra quanto a disciplina tem sido resistente a esses estudos. Há muito tempo, Michelle Perrot preocupava-se com a formação de guetos. A preocupação continua válida. É como se os Estudos de Gênero mantivessem um lugar "abrigado" para as mulheres. 
Nos títulos desses trabalhos historiográficos, apresentados no Fazendo Gênero 9, 17 deles traziam a palavra "mulher"; 56 traziam a categoria "mulheres"; 86 mencionavam "gênero"; e 12, a palavra "feminismo”. Das temáticas discutidas, mídia, etnia/raça, memória e corpo foram as mais frequentes. Convém destacar que, passados tantos anos, e se seguíssemos a analogia das "ondas", era de se esperar que os estudos de história não trouxessem mais em seus títulos a palavra "mulher" e, caso a tivessem, ela deveria estar referida à questão da "mulher como posicionalidade", assinalada por Claudia Lima, como já mencionamos. Contudo, podemos assegurar, não é disso que se trata. Os trabalhos que trazem a palavra "mulher" em seus títulos, e que foram apresentados no Fazendo Gênero 9, certamente ignoraram toda a crítica que, desde os anos 1970 , tem sido feita a essa palavra, por seu caráter generalizante. As tais "ondas", como se pode ver, não seguem as trajetórias esperadas.

Os estudos de gênero, aqui incluindo as categorias "mulher", "mulheres", "feminismo", "feminilidades", "masculinidades" e "relaçôes de gênero", têm buscado se colocar no centro do debate historiográfico, tentando fazer com que essas categorias se tornem comuns para quem pesquisa nesse campo. Ao mesmo tempo, como quaisquer outras, essas mesmas categorias vivem as instabilidades dos sentidos que lhes são atribuídos, resultado de lutas dentro do próprio campo. Encontra-se, ainda, portanto, nas margens do saber historiográfico. E, talvez por isso mesmo, busca novas maneiras de pensar essas margens, deslocando o centro, inventando novos percursos.

Podemos concluir, ainda, que as "ondas" do feminismo constituíram categorias de análise que foram se deslocando na direção dos países do Cone Sul, sempre com atraso e em diferentes momentos. Entretanto, o surgimento de uma nova categoria não eliminou as precedentes, que continuaram a existir. Em alguns países, como a Bolívia e o Paraguai, as três categorias, "mulher", "mulheres" e "relações de gênero", vieram juntas a partir dos anos 1980. Enquanto nos países do hemisfério norte observa-se a crítica à categoria "gênero" e o retorno da categoria "mulher", como um essencialismo instrumental, isso não ocorre na historiografia elaborada nos países do Cone Sul. Aí, a categoria "mulher" carrega, ainda, todo o essencialismo dos anos 1970. A grande novidade, nos países do Cone Sul, são os estudos pós-coloniais; porém, a historiografia local ainda não os incorporou.

Por outro lado, alguns trabalhos historiográficos, mesmo não tendo em seus objetivos discutir a questão de gênero nem focalizar as mulheres, têm integrado a discussão em suas problemáticas, fazendo aquilo que sempre foi a grande ambição desses estudos: tornar essa uma questão transversal, incorporando-a como uma categoria de análise que torna mais rica a escrita da história.

\section{Notas}

${ }^{1}$ Este artigo é resultado de dados coletados para a pesquisa "Do feminismo ao gênero. Circulação de teorias e apropriações no Cone Sul (1960-2008)”, iniciada em março de 2010, com financiamento do CNPq. Foi apresentado no Simpósio Internacional História e Margem, promovido pelo Programa de Pós-graduação em História Social da Universidade Federal do Rio de Janeiro (UFRJ), entre 18 e 20 de outubro de 2010. Parte dessa temática foi apresentada também em 6/12/2010 na Universidade de Toulouse, na França, no seminário da professora Sylvie Chaperon. Agradeço a Aimberê Araken Machado pela leitura e revisão.

${ }^{2}$ CHALHOUB, Sidney. Machado de Assis: historiador. São Paulo: Companhia das Letras, 2003.

${ }^{3}$ GOMES, Angela de Castro. Escrita de si, escrita da história: a título de prólogo. In: Escrita de si, escrita da história. Rio de Janeiro: FGV, 2004. p. 7-26.

${ }^{4}$ É um dado demográfico, uma vez que as estatísticas mostram que as mulheres vivem mais que os homens; além disso, sua condição subalterna de gênero as torna "guardiãs" da memória dos atos dos homens.

${ }^{5}$ HOBSBAWM, Eric. Era dos extremos. O breve século XX - 1914-1991. São Paulo: Companhia das Letras, 1995. p. 306.

${ }^{6}$ CHARTIER, Roger. Diferença entre os sexos e dominação simbólica. Tradução Sheila Schvarzman. Cadernos Pagu, Campinas, n. 4, 1995, p. 40.

${ }^{7}$ Ver THÉBAUD, Françoise. Políticas de gênero nas Ciências Humanas. O exemplo da disciplina histórica na França. Revista Espaço Plural, ano X, n. 21, 2o semestre, p. 33-42, 2009. p. 41. A notícia foi publicada no Journal Officiel de 22 de julho de 2005. 
${ }^{8}$ Ibidem, p. 34.

${ }^{9}$ Ibidem, p. 34-35.

${ }^{10}$ Uma exceção é o historiador E. P. Thompson, que agradece à esposa pelo trabalho que realizou, e que lhe permitiu fazer o livro.

${ }^{11}$ Entendo, como movimento feminista, as lutas que reconhecem as mulheres como oprimidas. É a afirmação de que as relações entre homens e mulheres não são inscritas na natureza e, portanto, são passíveis de transformação. Como movimento de mulheres, entendo que se trata de movimentos cujas reivindicações não são de direitos específicos das mulheres. Trata-se de movimentos sociais cujos componentes são, em sua maioria, mulheres. Ver, a esse respeito, Helena Hirata et al. Dictionnaire critique du féminisme, Paris, Presses Universitaires de France, 2000, p. 125-130. Por movimentos gays e de lésbicas, entendo as lutas que exigem que a sociedade reconheça indivíduos que consideram seus relacionamentos íntimos, com pessoas do mesmo sexo, como essenciais à sua identidade pessoal. No entanto, convém destacar que algumas lésbicas não querem ser consideradas pertencentes ao movimento gay. Querem ser identificadas como mulheres que se relacionam sexual e afetivamente com outras mulheres e que suas atitudes são "um ato político". Ver. ARRIOLA, Elvia R. Desigualdades de gênero: lésbicas, gays e teoria legal feminista. Revista Estudos Feministas, Florianópolis, v. 2, n. 2, 1994. p. 388-427.

${ }^{12}$ KOSELLECK, Reinhart. Futuro passado. Contribuição à semântica dos tempos históricos. Rio de Janeiro: PUC Rio, 2006. Neste texto, o autor examina o percurso de conceitos. Estamos extrapolando para a discussão, também, das categorias de análise.

${ }^{13}$ CHARTIER, Roger. A ordem dos livros: leitores, autores e bibliotecas na Europa entre os séculos XIV e XVIII. Brasília: Universidade de Brasília, 1999.

${ }^{14}$ HEMMINGS, Clare. Contando estórias feministas. Revista Estudos Feministas, Florianópolis, v. 17, n. 1, 2009.

${ }^{15}$ Ibidem. p. 9.

${ }^{16}$ Os trabalhos de Judith Butler mais citados são Corpos que importam. Sobre los limites materiales y discursivos del "sexo". Buenos Aires; Barcelona; México: Paidós, 2002 e Problemas de gênero. Feminismo e subversão da identidade. Rio de Janeiro: Civilização Brasileira, 2003.

${ }^{17}$ HAHNER, June E. A mulher no Brasil. Rio de Janeiro: Brasiliense, 1978.

${ }^{18}$ SAFFIOTI, Heleieth Iara Bongiovani. A mulher na sociedade de classes: mito e realidade. Petrópolis: Vozes, 1979.

${ }^{19}$ Consta no depoimento de Albertina de Oliveira Costa, em entrevista realizada por Joana Maria Pedro em São Paulo em 26/8/2006. Transcrita por Soraia Carolina de Mello.

${ }^{20}$ PRIORE, Mary Del. A mulher na história do Brasil. São Paulo: Contexto, 1988.

${ }^{21}$ LEITE, Miriam Lifchitz Moreira et al. A mulher do Rio de Janeiro no século XIX: um indice de referências em livros de viajantes estrangeiros. São Paulo: Fundação Carlos Chagas, 1982.

${ }^{22}$ MOTT, Maria Lucia de Barros. Submissão e resistência: a mulher na luta contra a escravidão. São Paulo: Contexto, 1988.

${ }^{23}$ BELLINI, Ligia. A coisa obscura: mulher, sodomia e Inquisição no Brasil Colônia. São Paulo: Brasiliense, 1989.

${ }^{24}$ MACEDO, José Rivair. A mulher na Idade Média: a situação no meio familiar, a atividade profissional, política, intelectual, exclusão, preconceitos e marginalidade. São Paulo: Contexto, 1990; PERNOUD, Régine. A mulher nos tempos das cruzadas. Campinas: Papirus, 1993; REIS, Maria Cândida Delgado. Tessitura de destinos: mulher e educação. São Paulo: EDUC, 1993.

${ }^{25}$ FIGUEIREDO, Luciano. O avesso da memória: cotidiano e trabalho da mulher em Minas Gerais no século XVIII. Rio de Janeiro: José Olympio/EdUnb, 1993.

${ }^{26}$ Ver, por exemplo, SILVA, Gilvan Ventura da; NADER, Maria Beatriz; FRANCO, Sebastião Pimentel (Orgs.). História, mulher e poder. Vitória: Edufes/PPGHis, 2006.

${ }^{27}$ SANTA CRUZ, Lucia et al. Tres ensayos sobre la mujer chilena: siglos XVIII-XIX-XX. Santiago do Chile: Universitaria, 1978.

${ }^{28}$ ROSSELLS, Beatriz. La mujer: una ilusion. Ideologías e imágenes de la mujer en Bolivia en el siglo XIX. La Paz: CIDEN, 1988.

${ }^{29}$ DUBY, Georges; PERROT, Michelle. História das mulheres no Ocidente. Porto: Afrontamento; São Paulo: Ebradil, $1993.5 \mathrm{v}$.

${ }^{30}$ EBRADIL - Empresa Brasileira de Distribuição de Livros Ltda.

${ }^{31}$ PRIORE, Mary Del (Org.). História das mulheres no Brasil. São Paulo: Contexto/Unesp, 1997.

${ }^{32}$ LOZANO, Fernanda Gil; PITA, Valeria Silvina; INI, María Gabriela (dirección). Historia de las mujeres en la Argentina. Buenos Aires: Taurus, 2000. Tomo II, Siglo XX.

${ }^{33}$ Trata-se de MORANT, Isabel (dir.). Historia de las mujeres en España y América Latina: Del siglo XX a los umbrales del XXI, v. IV. Madrid: Catedra, 2006.

${ }^{34}$ DIAS, Maria Odila Leite da Silva. Quotidiano e poder em São Paulo no século XIX. São Paulo: Brasiliense, 1984.

${ }^{35}$ ESTEVES, Martha de Abreu. Meninas perdidas: os populares e o cotidiano do amor no Rio de Janeiro da Belle Époque. Rio de Janeiro: Paz e Terra, 1989. 
${ }^{36}$ RAGO, Luzia Margareth. Do cabaré ao lar: a utopia da cidade disciplinar, Brasil 1890-1930. Rio de Janeiro: Paz e Terra, 1985.

${ }^{37}$ ENGEL, Magali. Meretrizes e doutores: saber médico e prostituição no Rio de Janeiro (1840-1890). São Paulo: Brasiliense, 1989.

${ }^{38}$ SOIHET, Rachel. Condição feminina e formas de violência: mulheres pobres e ordem urbana, 1890-1920. Rio de Janeiro: Forense Universitária, 1989.

39 SAMARA, Eni de Mesquita. As mulheres, o poder e a família: São Paulo século XIX. São Paulo: Marco Zero/Secretaria de Estado da Cultura de São Paulo, 1989.

${ }^{40}$ BRESCIANI, Maria Stella Martins. Apresentação. Revista Brasileira de História, n. 18, v. 9, 1989. p. 7-8.

${ }^{41}$ Rachel Soihet e eu publicamos um artigo intitulado "A emergência da pesquisa da História das Mulheres e das Relações de Gênero", na Revista Brasileira de História, v. 27, n. 54, p. 281-300, 2007.

${ }^{42}$ BARRANCOS, Dora. Mujeres en la sociedad argentina: una historia de cinco siglos. Buenos Aires: Sudamericana, 2007; BRAVO, María Celia; LOZANO, Fernanda Gil; PITA, Valeria (comps.). Historias de luchas, resistencias y representaciones. Mujeres en la Argentina, siglos XIX y XX. San Miguel de Tucumán: EDUNT, 2007.

${ }^{43}$ LAVRIN, Asunción. Mujeres, feminismo y cambio social en Argentina, Chile y Uruguay 1890-1940. Santiago, Chile: Ediciones de la Dirección de Bibliotecas, Archivos y Museos, 2005. Colección Sociedad y Cultura.

${ }^{44}$ GAVIOLA, Edda; LARGO, Eliana; PALESTRO, Sandra. Una historia necesaria. Mujeres en Chile: 1973-1990. Santiago de Chile, autoedición, 1994.

${ }^{45}$ AGUIRRE, Sonia Montecino (comp). Mujeres chilenas. Fragmentos de una historia. Santiago de Chile: Catalonia, 2008.

${ }^{46}$ YORE, Nadimy Perla; COLAZO, Carmen. Al rescate de nuestra historia. Asunción: Red de Mujeres Políticas, 2001.

${ }^{47}$ AQUINO, Olga Caballero A. Por orden superior: testimonios de mujeres víctimas de la dictadura en Paraguay: $1954-1989$. 3. edición corregida y aumentada. Asunción: Servilibro, 2003.

${ }^{48}$ TELESCA, Ignacio (coord.) Historia del Paraguay. Asunción: Taurus, 2010. p. 317-336.

${ }^{49}$ Conversa informal com a autora, em julho de 2010, em visita de campo a Assunção.

${ }^{50}$ SCOTT, Joan W. (1988b). Genre: Une catégorie utile d'analyse historique. Les Cahiers du GRIF, n. 37-38, printemps 1988, Le genre de l'histoire, p. 125-153.

${ }^{51}$ SCOTT, Joan. Gênero, uma categoria útil de análise histórica. Educação e Realidade, Porto Alegre, 16(2) 5-22, jul/dez. 1990.

52 Ibidem, p. 14.

${ }^{53}$ Idem.

${ }^{54}$ SAMARA, Eni de Mesquita; SOIHET, Rachel; MATOS, Maria Izilda S. de (Orgs). Gênero em debate: trajetória e perspectivas na historiografia contemporânea. São Paulo: EDUC, 1997.

55 SCHPUN, Mônica Raisa (Org.). Gênero sem fronteiras: oito olhares sobre mulheres e relaçôes de gênero. Florianópolis: Mulheres, 1997.

${ }^{56}$ ALBUQUERQUE JÚNIOR, Durval Muniz de. Nordestino: uma invenção do falo. Uma história do gênero masculino (Nordeste - 1920-1940). Maceió: Catavento, 2003.

${ }_{57}$ SILVA, Cristiani Bereta da. Homens e Mulheres em movimento: relaçôes de gênero e subjetividades no MST. Florianópolis: Movimento Atual, 2004.

${ }^{58}$ BARRANCOS, Dora. Historia y género. Buenos Aires: CEAL, 1993.

59 JELIN, Elizabeth. Los derechos de la cultura de género. Ediciones de las mujeres, Santiago de Chile, n. 25, 1997. p. 71-78.

${ }^{60}$ NAVARRO, Claudia Darrigrandi. Dramaturgia y género en el Chile de los sesenta. Santiago, Chile: LOM Ediciones, 2001. Colección Sociedad y Cultura.

${ }^{61}$ OLEA, Raquel; GRAU, Olga (comps). Volver a la memória. Santiago de Chile: LOM Ediciones/La Morada, 2001. Colección Contraseña/Estúdios de Género/Serie Casandra.

${ }^{62}$ ANDÚJAR, Andrea, DOMÍNGUEZ, Nora e RODRÍGUEZ, María Inés. Historia, género y política en los '70. Buenos Aires: Feminaria Editora, 2005.

${ }^{63}$ MARTINEZ, Paola. Género, política y revolución en los años setenta. Las mujeres del PRT-ERP. Buenos Aires: Imago Mundi, 2009.

${ }^{64}$ Cf. material disponível em: <www.eurosur.org/FLACSO/mujeres/paraguay/orga-1.htm>. Acesso em: 9 nov. 2005.

${ }^{65}$ Esta minibiografia foi feita por Ana Maria Veiga, que a entrevistou junto com Andrea Andújar, em maio de 2009.

${ }^{66}$ VEIGA, Ana Maria. Estudos de gênero na Argentina - olhares contemporâneos sobre o tema. Entrevista com Andrea Andújar e Alejandra Ciriza. História Unisinos. v. 14, n. 2, p. 226-232, mai./ago. 2010. p. 229.

${ }^{67}$ Reivindica o cyborg, um sujeito não propriamente feminino, nem mesmo humano. Ou seja, um feminismo não fundante, porque perdeu a razão de ser em sentido clássico, ao ter desaparecido a diferenciação sexual, por considerá-la desnecessária. 
${ }^{68}$ BUTLER, Judith; LACLAU, Ernesto; ZIZEK, Slavoj. Contingência, hegemonia, universalidad. Buenos Aires: FCE, 2003. p. 34.

${ }^{69}$ GARCIA, Teresa Aguilar. El sistema sexo-género en los movimientos feministas. Amnis. Revue de Civilisation Contemporaine Europes/Amériques, n. 8, 2008. Disponível em: <http://amnis.revues.org/537>. Acesso em 2 fev. 2010.

${ }^{70}$ BUTLER, Judith. Gender trouble. Feminism and the subersion of identity. New York: Routledge, 1990. p. 6.

${ }^{71}$ Categoria formulada por Gayatri Chakravorty Spivak.

${ }^{72}$ Ver, a este respeito, COSTA, Claudia de Lima. O tráfico do gênero. Cadernos Pagu, Campinas, n. 11, 1998. p. 138.

${ }^{73}$ Nessa discussão, Claudia de Lima Costa está citando ALCOFF, Linda. Cultural Feminism versus Poststructuralism: the identity crisis in feminist theory. Signs, 13 (3), 1988. Apud COSTA, Claudia de Lima. O sujeito do feminismo. Cadernos Pagu, Campinas, n. 19, 2002. p. 76.

${ }^{74}$ BIDASECA, Karina. Perturbando el texto colonial. Los estudios (pos) coloniales en América Latina. Buenos Aires: SD, 2010. p. 11.

${ }^{75}$ Gayatri Chakravorty Spivak é uma pensadora de origem indu, autora de “Podem falar os subalternos?”. Atualmente é professora na Universidade de Colúmbia.

${ }^{76}$ BIDASECA, K. Op. cit., p. 7.

77 Ibidem, p. 134.

${ }^{78}$ COSTA, Claudia de Lima; ÁVILA, Eliana. Gloria Anzaldúa, a consciência mestiça e "o feminismo da diferença”. Revista Estudos Feministas, Florianópolis, 13 (3): 320, set./dez. 2005.

${ }^{79}$ BIDASECA, K. Op. cit., p. 133.

${ }^{80}$ Ibidem, p. 140.

${ }^{81}$ CADENA, Marisol de la. "Las mujeres son más indias": etnicidad y género en una comunidad del Cusco. Estudios y debates, n. 1, julio 1991. p. 7-47.

${ }^{82}$ SALAZAR, Cecilia. Pueblo de humanos: metáforas corporales y diferenciación social indígena en Bolivia. Antropologia 2 año XXIV, n. 24, p. 5-26, 2006.

${ }^{83}$ Vestimentas como a pollera eram de uso espanhol. Composta por mantilla, la pollera de pliegues amplios y fruncidos en la cintura, las zapatillas y el rebozo de mangas anchas. Seu significado estava associado ao poder da hacienda. As índias e siervas usavam a acsu, a lliqlla y la ñañaca que persistem em regiōes mais tradicionais e empobrecidas do país. A este respeito, ver SALAZAR, Cecilia. Mujeres indígenas y cohesion nacional en Bolivia. In: FULLER OSORES, Norma. Jerarquías en jaque. Estudios de género en el área Andina. Lima/Peru: Red para el Desarrollo de las Cc. Ss, 2004, p. 251-281. Ver, principalmente, a página 259.

${ }^{84}$ BIDASECA, K. Op. cit., p. 140.

${ }^{85}$ ZUCCO, Maise. Os grupos de mulheres e os feminismos em Florianópolis: a importância atribuída às grandes capitais brasileiras. Anais do Fazendo Gênero 8 - Corpo, Violência e Poder. Florianópolis, 2008.

${ }^{86}$ PERROT, Michelle. Minha história das mulheres. São Paulo: Contexto, 2007.

\section{Referências}

AGUIRRE, Sonia Montecino (comp). Mujeres chilenas. Fragmentos de una historia. Santiago de Chile: Catalonia, 2008.

ALBUQUERQUE JÚNIOR, Durval Muniz de. Nordestino: uma invenção do falo. Uma história do gênero masculino (Nordeste - 1920-1940). Maceió: Catavento, 2003.

ALCOFF, Linda. Cultural Feminism versus Poststructuralism: the identity crisis in feminist theory. Signs, 13 (3), 1988.

ANDÚJAR, Andréa; DOMÍNGUEZ, Nora; RODRÍGUEZ, María Inés. Historia, género y politica en los '70. Buenos Aires: Feminaria Editora, 2005.

AQUINO, Olga Caballero A. Por orden superior: testimonios de mujeres víctimas de la dictadura en Paraguay: 1954-1989. 3a edición corregida y aumentada. Asunción: Servilibro, 2003.

ARRIOLA, Elvia R. Desigualdades de gênero: lésbicas, gays e teoria legal feminista. Revista Estudos Feministas, Florianópolis, v. 2, n. 2, 1994, p. 388-427.

BARRANCOS, Dora. Historia y género. Buenos Aires: CEAL, 1993. 
. Mujeres en la sociedad argentina: una historia de cinco siglos. Buenos Aires: Sudamericana, 2007.

BELLINI, Ligia. A coisa obscura: mulher, sodomia e Inquisição no Brasil Colônia. São Paulo: Brasiliense, 1989.

BIDASECA, Karina. Perturbando el texto colonial. Los estudios (pos) coloniales en América Latina. Buenos Aires: SD, 2010.

BRAVO, María Celia; LOZANO, Fernanda Gil; PITA, Valeria (comps.). Historias de luchas, resistencias y representaciones. Mujeres en la Argentina, siglos XIX y XX. San Miguel de Tucumán: EDUNT, 2007.

BRESCIANI, Maria Stella Martins. Apresentação. Revista Brasileira de História, n. 18, v. 9. 1989, p. 7-8.

BUTLER, Judith. Corpos que importam. Sobre los limites materiales y discursivos del "sexo". Buenos Aires; Barcelona; México: Paidós, 2002.

. Gender trouble. Feminism and the subersion of identity. New York: Routledge, 1990.

. Problemas de gênero. Feminismo e subversão da identidade. Rio de Janeiro: Civilização Brasileira, 2003.

BUTLER, Judith; LACLAU, Ernesto; ZIZEK, Slavoj. Contingência, hegemonia, universalidad. Buenos Aires: FCE, 2003.

CADENA, Marisol de la. "Las mujeres son más indias": etnicidad y género en una comunidad del Cusco. Estudios y debates, n. 1, julio 1991, p. 7-47.

CHALHOUB, Sidney. Machado de Assis: historiador. São Paulo: Companhia das Letras, 2003.

CHARTIER, Roger. A ordem dos livros: leitores, autores e bibliotecas na Europa entre os séculos XIV e XVIII. Brasília: Universidade de Brasília, 1999.

. Diferença entre os sexos e dominação simbólica. Tradução Sheila Schvarzman. Cadernos Pagu, Campinas, n. 4, 1995.

COSTA, Claudia de Lima. O sujeito do feminismo. Cadernos Pagu, Campinas, n. 19, 2002.

. O tráfico do gênero. Cadernos Pagu, Campinas, n. 11, 1998.

COSTA, Claudia de Lima; ÁVILA, Eliana. Gloria Anzaldúa, a consciência mestiça e "o feminismo da diferença”. Revista Estudos Feministas, Florianópolis, 13 (3): 320, set./dez. 2005.

DIAS, Maria Odila Leite da Silva. Quotidiano e poder em São Paulo no século XIX. São Paulo: Brasiliense, 1984.

DUBY, Georges; PERROT, Michelle. História das mulheres no Ocidente. Porto: Afrontamento; São Paulo: Ebradil, $1993.5 \mathrm{v}$.

ENGEL, Magali. Meretrizes e doutores: saber médico e prostituição no Rio de Janeiro (1840-1890). São Paulo: Brasiliense, 1989.

ESTEVES, Martha de Abreu. Meninas perdidas: os populares e o cotidiano do amor no Rio de Janeiro da Belle Époque. Rio de Janeiro: Paz e Terra, 1989.

FIGUEIREDO, Luciano. O avesso da memória: cotidiano e trabalho da mulher em Minas Gerais no século XVIII. Rio de Janeiro: José Olympio/EdUnb, 1993.

GARCIA, Teresa Aguilar. El sistema sexo-género en los movimientos feministas. Amnis. Revue de Civilisation Contemporaine Europes/Amériques, n. 8, 2008. Disponível em: <http://amnis.revues.org/537>

GAVIOLA, Edda; LARGO, Eliana; PALESTRO, Sandra. Una historia necesaria. Mujeres en Chile: 1973-1990. Santiago de Chile, autoedición, 1994.

GOMES, Angela de Castro. Escrita de si, escrita da história: a título de prólogo. In: Escrita de si, escrita da história. Rio de Janeiro: FGV, 2004. p. 7-26.

HAHNER, June E. A mulher no Brasil. Rio de Janeiro: Brasiliense, 1978.

HEMMINGS, Clare. Contando estórias feministas. Revista Estudos Feministas, Florianópolis, v. 17, n. 1, 2009. HIRATA, Helena et alii. Dictionnaire critique du féminisme, Paris, Presses Universitaires de France, 2000.

HOBSBAWM, Eric. Era dos extremos. O breve século XX - 1914-1991. São Paulo: Companhia das Letras, 1995.

JELIN, Elizabeth. Los derechos de la cultura de género. Ediciones de las mujeres, Santiago de Chile, n. 25, 1997, p. 71-78.

KOSELLECK, Reinhart. Futuro passado. Contribuição à semântica dos tempos históricos. Rio de Janeiro: PUCRio, 2006. 
LAVRIN, Asunción. Mujeres, feminismo y cambio social en Argentina, Chile y Uruguay 1890-1940. Santiago, Chile: Ediciones de la Dirección de Bibliotecas, Archivos y Museos, 2005 (Colección Sociedad y Cultura).

LEITE, Miriam Lifchitz Moreira et al. A mulher do Rio de Janeiro no século XIX: um indice de referências em livros de viajantes estrangeiros. São Paulo: Fundação Carlos Chagas, 1982.

LOZANO, Fernanda Gil; PITA, Valeria Silvina; INI, María Gabriela (dirección). Historia de las mujeres en la Argentina. Buenos Aires: Taurus, 2000. Tomo II, Siglo XX.

MACEDO, José Rivair. A mulher na Idade Média: a situação no meio familiar, a atividade profissional, politica, intelectual, exclusão, preconceitos e marginalidade. São Paulo: Contexto, 1990.

MARTINEZ, Paola. Género, política y revolución en los años setenta. Las mujeres del PRT-ERP. Buenos Aires: Imago Mundi, 2009.

MORANT, Isabel (dir.). Historia de las mujeres en España y América Latina: del siglo XX a los umbrales del XXI, v. IV. Madrid: Catedra, 2006.

MOTT, Maria Lucia de Barros. Submissão e resistência: a mulher na luta contra a escravidão. São Paulo: Contexto, 1988.

NAVARRO, Claudia Darrigrandi. Dramaturgia y género en el Chile de los sesenta. Santiago, Chile: LOM Ediciones, 2001. Colección Sociedad y Cultura.

OLEA, Raquel; GRAU, Olga (comps). Volver a la memória. Santiago de Chile: LOM Ediciones/La Morada, 2001. Colección Contraseña/Estúdios de Género/Serie Casandra.

PEDRO, Joana Maria; SOIHET, Rachel. A emergência da pesquisa da História das Mulheres e das Relações de Gênero. Revista Brasileira de História, v. 27, n. 54, 2007, p. 281-300.

PERNOUD, Régine. A mulher nos tempos das cruzadas. Campinas: Papirus, 1993.

PERROT, Michelle. Minha história das mulheres. São Paulo: Contexto, 2007.

PRIORE, Mary Del (Org). História das mulheres no Brasil. São Paulo: Contexto/Unesp, 1997. . A mulher na história do Brasil. São Paulo: Contexto, 1988.

RAGO, Luzia Margareth. Do cabaré ao lar: a utopia da cidade disciplinar, Brasil 1890-1930. Rio de Janeiro: Paz e Terra, 1985.

REIS, Maria Cândida Delgado. Tessitura de destinos: mulher e educação. São Paulo: EDUC, 1993.

ROSSELLS, Beatriz. La mujer: una ilusion. Ideologias e imágenes de la mujer en Bolivia en el siglo XIX. La Paz: CIDEN, 1988.

SAFFIOTI, Heleieth Iara Bongiovani. A mulher na sociedade de classes: mito e realidade. Petrópolis: Vozes, 1979.

SALAZAR, Cecilia. Mujeres indígenas y cohesion nacional en Bolivia. In: FULLER OSORES, Norma. Jerarquías en jaque. Estudios de género en el área Andina. Lima/Peru: Red para el Desarrollo de las Cc. Ss, 2004, p. 251-281.

. "Pueblo de humanos: metáforas corporales y diferenciación social indígena en Bolivia". Antropologia año XXIV, n. 24, 2006, p. 5-26.

SAMARA, Eni de Mesquita. As mulheres, o poder e a família: São Paulo século XIX. São Paulo: Marco Zero/ Secretaria de Estado da Cultura de São Paulo, 1989.

SAMARA, Eni de Mesquita; SOIHET, Rachel; MATOS, Maria Izilda S. de (Orgs.). Gênero em debate: trajetória e perspectivas na historiografia contemporânea. São Paulo: EDUC, 1997.

SANTA CRUZ, Lucia et alii. Tres ensayos sobre la mujer chilena: siglos XVIII-XIX-XX. Santiago do Chile: Universitaria, 1978.

SCHPUN, Mônica Raisa (Org.). Gênero sem fronteiras: oito olhares sobre mulheres e relaçôes de gênero. Florianópolis: Mulheres, 1997.

SCOTT, Joan W. Genre: une catégorie utile d'analyse historique. Les Cahiers du GRIF, n. 37-38, printemps 1988, p. 125-153.

SCOTT, Joan. Gênero, uma categoria útil de análise histórica. Educação e Realidade, Porto Alegre, 16(2), jul/ dez. 1990, p. 5-22.

SILVA, Cristiani Bereta da. Homens e Mulheres em movimento: relaçôes de gênero e subjetividades no MST. Florianópolis: Movimento Atual, 2004. 
SILVA, Gilvan Ventura da; NADER, Maria Beatriz; FRANCO, Sebastião Pimentel (Orgs.). História, mulher e poder. Vitória: Edufes/PPGHis, 2006.

SOIHET, Rachel. Condição feminina e formas de violência: mulheres pobres e ordem urbana, 1890-1920. Rio de Janeiro: Forense Universitária, 1989.

TELESCA, Ignacio (coord.) Historia del Paraguay. Asunción: Taurus, 2010.

THÉBAUD, Françoise. Políticas de gênero nas Ciências Humanas. O exemplo da disciplina histórica na França. Espaço Plural, ano X, n. 21, $2^{\circ}$ semestre, 2009, p. 33-42.

VEIGA, Ana Maria. Estudos de gênero na Argentina - olhares contemporâneos sobre o tema. Entrevista com Andrea Andújar e Alejandra Ciriza. História Unisinos. v. 14, n. 2, mai./ago. 2010. p. 229, p. 226-232.

YORE, Nadimy Perla; COLAZO, Carmen. Al rescate de nuestra historia. Asunción: Red de Mujeres Políticas, 2001.

ZUCCO, Maise. Os grupos de mulheres e os feminismos em Florianópolis: a importância atribuída às grandes capitais brasileiras. Anais do Fazendo Gênero 8 - Corpo, Violência e Poder. Florianópolis, 2008.

\section{RESUMO}

Com a ambição de se tornar uma categoria de análise presente nas mais diversas narrativas históricas, a categoria "gênero", no Brasil e em outros países do Cone Sul, teve um percurso muito diferente em relação ao que se costuma ver na historiografia norte-americana e na francesa. Associada à instrumentalização pelas ONGs e à institucionalização pelos governos democráticos que se instalaram no Cone Sul após as ditaduras, essa categoria é, muitas vezes, pensada como distante do feminismo e da história das mulheres. Disputas políticas no campo acadêmico e militante repercutem no seu uso. Discutir as críticas, e a maneira como essa categoria tem sido empregada nos textos de história no Brasil e nos demais paises do Cone Sul, é o que pretende este artigo.

Palavras-chave: gênero, feminismo, história, Brasil, Cone Sul.

\section{ABSTRACT}

Gender, as an ambitioning category of analysis which permeates a wide range of historical narratives, has come through a rather varied path in Brazil and in other Southern Cone countries in comparison to the North-American and French historiographies. While having been associated to instrumental practices by NGOs, and to institutionalization by the democratic governments which have been implemented in the Southern Cone after the end of their respective dictatorships, gender as a category has been often seen as something distant from feminism and women's history. Its use is reflected on political disputes in both academic and militant fields. This article intends to discuss criticism, and the way in which this category has been used in History textbooks in Brazil and other Southern Cone countries.

Keywords: gender, feminism, History, Brasil, Southern Cone. 